Tropical Journal of Pharmaceutical Research September 2015; 14 (9): 1685-1689

ISSN: 1596-5996 (print); 1596-9827 (electronic)

(C) Pharmacotherapy Group, Faculty of Pharmacy, University of Benin, Benin City, 300001 Nigeria.

All rights reserved.

Available online at http://www.tjpr.org

Original Research Article

http://dx.doi.org/10.4314/tjpr.v14i9.20

\title{
Gas Chromaotography-Mass Spectrometry Analysis of Insecticidal Essential Oil Derived from Chinese Ainsliaea fragrans Champ ex Benth (Compositae)
}

\author{
Mei Ping Zhao, Xin Chao Liu, Qi Zhi Liu and Zhi Long Liu* \\ Department of Entomology, China Agricultural University, 2 Yuanmingyuan West Road, Haidian District, Beijing 100193, China
}

*For correspondence: Email: zhilongliu@cau.edu.cn; Tel.: +86-10-62732800; Fax: +86-10-62732800

Received: 6 January 2015

Revised accepted: 27 July 2015

\begin{abstract}
Purpose: To investigate the chemical composition and insecticidal activity of the essential oil of the aerial parts of Ainsliaea fragrans against maize weevils (Sitophilus zeamais).

Methods: The essential oil of A. fragrans aerial parts was obtained by hydrodistillation and analyzed by gas chromatography (GC) and gas chromaotography-mass spectrometry (GC-MS). Contact toxicity of the essential oil and its major constituents was determined by topical application against S. zeamais.

Results: A total of 30 components of the essential oil were identified. The major constituents were myristicin (41.3\%), elemicine (11.9\%), cis-isosafrole (11.5\%), borneol (9.1\%) and caryophyllene (8.8 $\%)$. The essential oil of $A$. fragrans exhibited contact toxicity against $S$. zeamais with $L C_{50}$ value of 50.7 $\mu \mathrm{g} / \mathrm{adult}$. Elemicine possessed the strongest contact toxicity $\left(L C_{50}=13.5 \mu \mathrm{g} / \mathrm{adult}\right)$ while cis-isosafrole, myristicin, caryophyllene and borneol had $L C_{50}$ values of $31.2 \mu \mathrm{g} / \mathrm{adult}, 43.4 \mu \mathrm{g} / \mathrm{adult}, 57.9 \mu \mathrm{g} / \mathrm{adult}$, and $98.4 \mu \mathrm{g} / \mathrm{adult}$, respectively.

Conclusion: The study indicates that the essential oil of $A$. fragrans aerial parts and its major constituents have a potential for development into natural insecticides for the control of grain storage insects.
\end{abstract}

Keywords: Ainsliaea fragrans, Sitophilus zeamais, Contact toxicity, Elemicine, Essential oil, Grain storage

Tropical Journal of Pharmaceutical Research is indexed by Science Citation Index (SciSearch), Scopus, International Pharmaceutical Abstract, Chemical Abstracts, Embase, Index Copernicus, EBSCO, African Index Medicus, JournalSeek, Journal Citation Reports/Science Edition, Directory of Open Access Journals (DOAJ), African Journal Online, Bioline International, Open-J-Gate and Pharmacy Abstracts

\section{INTRODUCTION}

During the screening program for new agrochemicals from Chinese medicinal herbs and wild plants, the essential oil of Ainsliaea fragrans Champ. ex Benth. aerial parts was found to possess insecticidal toxicity against maize weevils (Sitophilus zeamais Motsch.). The genus Ainsliaea belongs to the family Compositae (Asteraceae) and is distributed in east part of Asia with about 50 species in the world, of which 40 species (28 endemic) are distributed in China [1]. A. fragrans is a perennial herb (25 - $60 \mathrm{~cm}$ tall) distributed in Anhui, Fujian, Guangdong, Guangxi, Guizhou, Hubei, Hunan, Jiangsu, Jiangxi, Sichuan, Taiwan, Yunnan, and Zhejiang Provinces in China [1]. The whole herb of this plant is widely used in traditional Chinese medicine for the treatment of coughing up blood, jaundice with damp-heat pathogen, edema, and superficial infection [2].

The aqueous extract of $A$. fragrans aerial parts is widely applied in treating cervicitis, endometritis, and pelvic inflammation, and its clinical effects are significant in China [3]. From the aerial parts 
of $A$. fragrans, sesquiterpenoids, sesquiterpene lactones, sesquiterpene lactone glycosides, coumarins, flavonoids, triterpenoids, lignans and phenolic acids have been isolated [2-5]. The chemical composition of the essential oils derived from $A$. fragrans has also been determined [6,7]. However, literature survey shows that there is no report on insecticidal activity of the essential oil derived from $A$. fragrans aerial parts. Thus, the objective of this study was to investigate the chemical constituents and insecticidal activity of the essential oil of $A$. fragrans aerial parts and its major constituents against maize weevils.

\section{EXPERIMENTAL}

\section{Plant collection and identification}

The aerial parts of $A$. fragrans $(10 \mathrm{Kg}$ ) were harvested from Lishui City, Zhejiang Province, China $\left(27.54^{\circ} \mathrm{N}\right.$ and $\left.119.20^{\circ} \mathrm{E}\right)$ in September 2014. The plant was identified by Dr. Liu, Q.R. (College of Life Sciences, Beijing Normal University, Beijing 100875, China), and a voucher specimen (no. ENTCAU-CompositaeXinxiangtuerfeng-016) was deposited at the musem of Department of Entomology, China Agricultural University, Beijing, China.

\section{Extraction and isolation of essential oils}

The sample was cut into small pieces and subjected to hydro distillation using a modified Clevenger-type apparatus for $6 \mathrm{~h}$. Anhydrous $\mathrm{Na}_{2} \mathrm{SO}_{4}$ was used to remove water after extraction. The essential oil was stored in airtight containers in a refrigerator at $4{ }^{\circ} \mathrm{C}$ for subsequent experiments.

\section{Analysis of the essential oils}

Gas chromatographic analysis was performed using Hewlett-Packard 5890 gas chromatograph equipped with a flame ionization detector and fused silica capillary column HP-5 (5\% diphenyl and $95 \%$ dimethylpolysyloxane, $30 \mathrm{~m} \times 0.25$ $\mathrm{mm}, 0.25 \mu \mathrm{m}$ film thickness), at a flow rate of 1 $\mathrm{mL} \mathrm{min}^{-1}$. Temperature was programmed from 60 to $280{ }^{\circ} \mathrm{C}$ (at a rate of $2{ }^{\circ} \mathrm{C} \mathrm{min}^{-1}$ ); injector and detector temperatures were 270 and $300{ }^{\circ} \mathrm{C}$, respectively. The components of the essential oils were separated and identified by gas chromatography-mass spectrometry (GC - MS) using Agilent 6890N gas chromatography coupled to Agilent 5973N mass selective detector. The system was equipped with a flame ionization detector and capillary column with HP$5 \mathrm{MS}(30 \mathrm{~m} \times 0.25 \mathrm{~mm} \times 0.25 \mu \mathrm{m})$. GC settings were as follows: the initial oven temperature was held at $60{ }^{\circ} \mathrm{C}$ for $1 \mathrm{~min}$ and ramped at $10{ }^{\circ} \mathrm{C}$ $\mathrm{min}^{-1}$ to $180{ }^{\circ} \mathrm{C}$ where it was held for $1 \mathrm{~min}$, and then ramped at $20{ }^{\circ} \mathrm{C} \mathrm{min}^{-1}$ to $280{ }^{\circ} \mathrm{C}$ and held there for $15 \mathrm{~min}$. The injector temperature was maintained at $270{ }^{\circ} \mathrm{C}$. The samples $(1 \mu \mathrm{L}$, diluted to $100: 1$ with acetone) were injected, with a split ratio of $1: 10$. The carrier gas was helium at a flow rate of $1.0 \mathrm{ml} \mathrm{min}^{-1}$. Spectra were obtained over the scan range 20 to $550 \mathrm{~m} / \mathrm{z}$ at 2 scans $\mathrm{s}^{-1}$. Constituents were identified by gas chromatography by comparison of their retention indices with those published in the literature or with those of authentic compounds available in our laboratories. The retention indices were determined in relation to a homologous series of $n$-alkanes $\left(\mathrm{C}_{8}-\mathrm{C}_{24}\right)$ under the same operating conditions. Further identification was made by comparison of their mass spectra with those stored in NIST 05 and Wiley 275 libraries or with mass spectra from literature [8]. Relative percentages of the oil components were calculated based on GC peak areas without using correction factors.

\section{Chemicals}

Borneol, caryophyllene, elemicine, cis-isosafrole, and myristicin were purchased from purchased from Aladdin-Reagent Company (Shanghai, China). Pyrethrum extract (25\% pyrethrin I and pyrethrin II) was purchased from Fluka Chemie and used as a positive control.

\section{Insects}

S. zeamais was obtained from laboratory cultures in the dark in incubators at $27-29{ }^{\circ} \mathrm{C}$ and $70-80 \%$ relative humidity. Adult $S$. zeamais insects were reared on whole wheat at 12 - $13 \%$ moisture content in glass jars (diameter $85 \mathrm{~mm}$, height $130 \mathrm{~mm}$ ). Laboratory bioassays were done within one week after unsexed adult collection. All containers housing insects and the Petri dish used in the experiments were made escape-proof with a coating of polytetrafluoroethylene (Fluon, Blades Biological, UK).

\section{Contact toxicity test}

The contact toxicity of the essential oil of $A$. fragrans aerial parts against $S$. zeamais adults was measured as described in the previous reports [9]. Range-finding studies were run to determine the appropriate testing concentrations. A serial dilution of the essential oil (6 concentrations, $3.5-10.0 \%$, v/w) was prepared in $\mathrm{n}$-hexane. Aliquots of $0.5 \mu \mathrm{L}$ of the dilutions were applied topically to the dorsal thorax of the 
insects, using a Burkard Arnold microapplicator. Controls were determined using n-hexane. Both treated and control insects were then transferred to glass vials (10 insects per vial) with culture media and kept in incubators for $24 \mathrm{~h}$. Then mortality of insects was observed.

\section{Statistical analysis}

The results from all replicates in contact toxicity tests were subjected to Probit analysis [10] using PriProbit Program V1.6.3 to determine $\mathrm{LC}_{50}$ values and their $95 \%$ confidence intervals [11]. Samples for which the $95 \%$ fiducial limits did not overlap were considered to be significantly different.

\section{RESULTS}

The essential oil of $A$. fragrans was yellow with a yield of $0.06 \%(\mathrm{v} / \mathrm{w})$ and density of $0.82 \mathrm{~g} / \mathrm{ml}$. A total of 30 components of the essential oil were identified, accounting for $98.7 \%$ of the total oil. The major compounds in the essential oil were myristicin $(41.3 \%)$, elemicine $(11.9 \%)$, cisisosafrole $(11.5 \%)$, borneol $(9.1 \%)$ and caryophyllene $(8.8 \%) \quad$ (Table 1). Phenylpropanoids represent 4 of 30 compounds, corresponding to $65.2 \%$ of the whole oil while 12 and 14 of the 32 constituents were monoterpenoids and sesquiterpenoids, respectively (13.3 \% and $21.2 \%$ of the whole essential oil, respectively) (Table 1 ).

The essential oil of $A$. fragrans exhibited contact toxicity against $S$. zeamais with a $\mathrm{LC}_{50}$ value of $50.7 \mu \mathrm{g} /$ adult (Table 2). Among 5 major constituents, elemicine possessed strongest contact toxicity $\left(\mathrm{LC}_{50}=13.5 \mu \mathrm{g} / \mathrm{adult}\right)$ while cisisosafrole, myristicin, caryophyllene and borneol had LC $_{50}$ values of $31.2 \mu \mathrm{g} /$ adult, $43.4 \mu \mathrm{g} /$ adult, $57.9 \mu \mathrm{g} /$ adult, and $98.4 \mu \mathrm{g} /$ adult, respectively (Table 2).

Table 1: The main compounds of the essential oil of Ainsliaea fragrans aerial parts

\begin{tabular}{|c|c|c|c|}
\hline Peak no. & Compound & Retention index & (\%) \\
\hline & Monoterpenoids & & 12.3 \\
\hline 1 & a-Pinene & 931 & 0.1 \\
\hline 2 & $\beta$-Pinene & 981 & 0.1 \\
\hline 3 & $\beta$-Myrcene & 991 & 0.5 \\
\hline 4 & Limonene & 1029 & 0.1 \\
\hline 5 & 1,8-Cineole & 1031 & 0.6 \\
\hline 6 & $(Z)$ - $\beta$-Ocimene & 1037 & 0.2 \\
\hline 7 & Linalool & 1094 & 0.4 \\
\hline 8 & Camphor & 1143 & 0.1 \\
\hline 9 & Borneol & 1174 & 9.1 \\
\hline 10 & 4-Terpineol & 1176 & 0.2 \\
\hline 11 & $\alpha$-Terpineol & 1188 & 0.6 \\
\hline \multirow[t]{2}{*}{12} & Bornyl acetate & 1287 & 0.3 \\
\hline & Sesquiterpenoids & & 21.2 \\
\hline 13 & a-Cubebene & 1349 & 0.9 \\
\hline 14 & Copaene & 1375 & 2.2 \\
\hline 15 & Caryophyllene & 1420 & 8.8 \\
\hline 16 & a-Caryophyllene & 1449 & 3.2 \\
\hline 17 & $(E)-\beta$-Farnesene & 1457 & 0.7 \\
\hline 18 & Alloaromadendrene & 1462 & 1.5 \\
\hline 19 & Aristolene & 1484 & 1.1 \\
\hline 20 & Germacrene D & 1486 & 0.1 \\
\hline 21 & $\delta$-Cadinene & 1525 & 0.1 \\
\hline 22 & trans-Nerolidol & 1564 & 0.6 \\
\hline 23 & Spathulenol & 1574 & 0.3 \\
\hline 24 & Caryophyllene oxide & 1578 & 1.5 \\
\hline 25 & T-Cadinol & 1642 & 0.1 \\
\hline \multirow[t]{2}{*}{26} & $\beta$-Eudesmol & 1648 & 0.1 \\
\hline & Phenylpropanoids & & 65.2 \\
\hline 27 & Eugenol & 1356 & 0.5 \\
\hline 28 & cis-Isosafrole & 1306 & 11.5 \\
\hline 29 & Myristicin & 1523 & 41.3 \\
\hline 30 & Elemicine & 1554 & 11.9 \\
\hline
\end{tabular}

${ }^{*} R l$, retention index as determined on a HP-5MS column using the homologous series of $n$-hydrocarbons 
Table 2: Contact toxicity of Ainsliaea fragrans essential oil and its major constituents against adult Sitophilus zeamais

\begin{tabular}{lcccc}
\hline Treatment & $\mathbf{L C}_{\mathbf{5 0}}(\boldsymbol{\mu g}$ /adult) & 95\% fiducial limits & Slope \pm SD & Chi-square value \\
\hline Essential oil & 50.7 & $47.4-54.1$ & $3.2 \pm 0.2$ & 13.2 \\
Borneol & 98.4 & $91.7-106.4$ & $4.6 \pm 0.4$ & 10.9 \\
Caryophyllene & 57.9 & $53.5-62.3$ & $4.7 \pm 0.4$ & 8.3 \\
Elemicine & 13.5 & $12.5-14.6$ & $3.4 \pm 0.2$ & 15.8 \\
cis-Isosafrole & 31.2 & $29.3-33.7$ & $3.9 \pm 0.4$ & 13.9 \\
Myristicin & 43.4 & $40.1-46.9$ & $2.7 \pm 0.2$ & 12.2 \\
Pyrethrum extract & 4.5 & $4.1-4.8$ & $0.7 \pm 0.1$ & 13.5 \\
\hline
\end{tabular}

\section{DISCUSSION}

The main constituents of the essential oil of $A$. fragrans aerial parts were myristicin, elemicine, cis-isosafrole, borneol and caryophyllene. Its chemical composition is noticeably different from that collected from other locations in China. For example, it varies substantially from the chemical compositions of the essential oils derived from five $A$. fragrans samples collected from Jiangxi Province, China [6]. This suggests that great variations in chemical composition of essential oil of $A$. fragrans aerial parts may be due to harvest time, geographical location, climatic and seasonal factors, as well as storage duration of the medicinal herbs. Thus, essential oil standardization is needed before $A$. fragrans essential oil prior to releasing the products for to the market.

The essential oil of $A$. fragrans aerial parts exhibited contact toxicity against $S$. zeamais. However, compared with positive control (Pyrethrum extract), $A$. fragrans essential oil showed 11 times lower acute toxicity to maize weevils. However, compared with contact toxicity of the other essential oils reported in the literature and which were tested using a similar bioassay, the essential oil obtained in the present study exhibited the same or stronger contact toxicity against maize weevils [12-16]. Among the five major constituents, elemicine exhibited the strongest contact toxicity against maize weevils and three phenylpropanoids possessed stronger toxicity than the crude oil. Caryophyllene showed the same level of toxicity as the essential oil, and borneol was less toxic than the essential oil. It appears that the acute toxicity of the essential oil may be due to the three phenylpropanoids.

In a previous report, elemicine exhibited acaricidal activity against larval cattle tick, Rhipicephalus (Boophilus) microplus [17]. Morover, myristicin was shown to have contact and fumigant toxicity against several insects and mites, including houseflies (Musca domestica) [20], hairy caterpillars (Spilarctia obliqua) [18], armyworms (Pseudaletia unipuncta) [19], and house dust mites (Dermatophagoides farinae and $D$. pteronyssinus) and mould mites (Tyrophagus putrescentiae) [20]. Myristicin was also demonstrated to exhibit strong synergistic activity because it has been demonstrated to possess strong inhibitory effects on many P450s [22].

The foregoing suggest that the essential oil of $A$. fragrans and its five major components especially three phenylpropanoids have some promise as a possible natural insecticide for the control of grain storage insects. However, to develop a practical application for the essential oil and its major constituents as novel insecticides, further research into their safety in humans is needed. Additional studies on the development of formulations are also necessary to improve efficacy and stability as well as to reduce cost.

\section{CONCLUSION}

The essential oil of $A$. fragrans aerial parts and its major constituents possess some activity against maize weevils but needs to be further evaluated for safety in humans and to enhance its insecticidal activity.

\section{ACKNOWLEDGEMENT}

This work was funded by National Key Technology Research and Development Program of Ministry of Science and Technology of China (Grant no. 2014BAD23B02). The authors thank Dr. QR Liu of the College of Life Sciences, Beijing Normal University, Beijing, China for the identification of the investigated plant.

\section{REFERENCES}

1. Zhang DX, Hartley TG, Mabberley DJ. Flora of China. 2003. [cited 2015 July 8]. Available from: http://www.efloras.org/florataxon.aspx?flora_id=2\&tax on_id=200023026

2. Jiangsu New Medical College. Dictionary of Chinese Herbal Medicine. Shanghai Science \& Technology Press, Shanghai, China, 1977; p 1435.

Trop J Pharm Res, September 2015; 14(9): 1688 
3. Wang $H$, Wu $T$, Yan M, Liu G, Li P, Zhang XQ, Ye WC, Zhang $L Y$. Sesquiterpenes from Ainsliaea fragrans and their inhibitory activities against cyclooxygenases-1 and 2. Chem Pharm Bull 2009; 57: 597-599.

4. Bohlmann F, Chen ZL. Naturally occurring terpene derivatives. Part 426. Guaianolides from Ainsliaea fragrans. Phytochemistry 1982; 21: 2120-2122.

5. Feng $F$, Chen $M H$, Xing CX, Liu WY, Xie N. Two novel sesquiterpenoids from Ainsliaea fragrans Champ. $J$ Asian Nat Prod Res 2009; 11: 855-859.

6. Ge F, Wu AM, Hao XB, Lai XW, Liu QH. Analysis of volatile oil components from the whole plant of Ainsliaea fragrans Champ. J Nanchang Univ 2007; 31: 467-472.

7. Zhao H, Wang W, Zhao SS, Jin JY, Kang WY. Analysis of volatile compounds from Ainsliaea fragrans in Guizhou by SPME-GC/MS. Chin J Exp Tradit Med Formulae 2011; 17: 135-137.

8. Adams RP. Identification of Essential Oil Components by Gas Chromatograph /Mass Spectrometry. 4th ed. Allured Publishing Corpoartion, Carol Stream, USA, 2007.

9. Liu ZL, Goh SH, Ho SH. Screening of Chinese medicinal herbs for bioactivity against Sitophilus zeamais Mostchulsky and Tribolium castaneum (Herbst). J Stored Prod Res 2007; 43: 290-296.

10. Finney DJ. Probit analysis. 3rd ed. Cambridge University, London. 1971.

11. Sakuma M. Probit analysis of preference data. Appl Entomol Zool 1998; 33: 339-347.

12. Liu ZL, Chu SS, Liu QR Chemical composition and insecticidal activity against Sitophilus zeamais of the essential oils of Artemisia capillaris and Artemisia mongolica. Molecules 2010; 15: 2600-2608.

13. Chu SS, Liu QR, Liu ZL. Insecticidal activity and chemical composition of the essential oil of Artemisia vestita from China. Biochem Syst Ecol 2010; 38: 489-492.
14. Liu ZL, Liu QR, Chu SS, Jiang GH. Insecticidal activity and chemical composition of the essential oils of Artemisia lavandulaefolia and Artemisia sieversiana from China. Chem Biodivers 2010; 7: 2040-2045.

15. Chu SS, Liu SL, Jiang GH, Liu ZL. Composition and toxicity of essential oil of Illicium simonsii Maxim (Illiciaceae) fruit against the maize weevils. Rec Nat Prod 2010; 4: 205-210.

16. Chu SS, Liu QR, Jiang GH, Liu ZL. Chemical composition and insecticidal activity of the essential oil of Amethystea caerulea L. Nat Prod Res 2012; 26:1207121210.

17. Hue T, Cauquil L, Fokou JBH, Dongmo PMJ, BakarngaVia I, Menut C. Acaricidal activity of five essential oils of Ocimum species on Rhipicephalus (Boophilus) microplus larvae. Parasitol Res 2015; 114: 91-99.

18. Fuhremann TW, Lichtenstein EP. Insecticide toxicity and degradation in houseflies as affected by naturally occurring food plant components. J Agric Food Chem 1979; 27: 87-91.

19. Srivastava S, Gupta MM, Prajapati V, Tripathi AK, Kumar S. Insecticidal activity of myristicin from Piper mullesua. Pharm Biol 2001; 39: 226-229.

20. Passreiter CM, Akhtar $Y$, Isman MB. Insecticidal activity of the essential oil of Ligusticum mutellina roots. $Z$ Naturforsch 2005; 60(C): 411-414.

21. Song HY, Yang JY, Suh JW, Lee HS. Acaricidal activities of apiol and its derivatives from Petroselinum sativum seeds against Dermatophagoides pteronyssinus, Dermatophagoides farinae, and Tyrophagus putrescentiae. J Agric Food Chem 2011; 59: 77597764.

22. Mao W, Zangerl AR, Berenbaum MR, Schuler MA. Metabolism of myristicin by Depressaria pastinacella CYP6AB3v2 and inhibition by its metabolite. Insect Biochem Mol Biol 2008; 38: 645-651. 